\title{
Pengaruh Jarak Tanam dan Dosis Pupuk NPK terhadap Pertumbuhan dan Hasil Tanaman Bawang Putih (Allium sativum L.) di Dataran Rendah
}

\author{
The Effect of Plant Spacing and Dosage of NPK Fertilizer and Yield of Garlic \\ (Allium sativum L.) in Lowland
}

\author{
Jaksa Metuah $^{1}$, Elly Kesumawati ${ }^{1}$, Rita Hayati ${ }^{1}$ \\ ${ }^{1}$ Program Studi Agroteknologi PSDKU Gayo Lues, Fakultas Pertanian, Universitas Syiah Kuala \\ jaksa161agro@gmail.com
}

\begin{abstract}
Abstrak. Penelitian ini bertujuan untuk mengetahui pengaruh jarak tanam dan dosis pupuk NPK yang tepat dan interaksi antara kedua faktor tersebut terhadap pertumbuhan dan hasil tanaman bawang putih di dataran rendah. Penelitian ini dilaksanakan di Kebun Percobaan II sektor Timur dan Laboratorium Iptek Perbenihan Fakultas Pertanian Universitas Syiah Kuala berlangsung dari Januari sampai dengan April 2021. Rancangan penelitian yang digunakan adalah Rancangan Acak Kelompok faktorial $3 \times 3$ dengan 3 ulangan. Faktor yang diteliti adalah jarak tanam yang terdiri dari 3 taraf yaitu $10 \mathrm{~cm} \times 10 \mathrm{~cm}, 10 \mathrm{~cm} \times 15 \mathrm{~cm}, 10 \mathrm{~cm} \times 20 \mathrm{~cm}$ dan dosis pemupukan NPK terdiri dari 3 taraf yaitu 400, 600 dan $800 \mathrm{~kg}$ ha- ${ }^{1}$. Hasil penelitian menunjukkan bahwa jarak tanam berpengaruh sangat nyata terhadap bobot umbi per petak dan potensi hasil, berpengaruh nyata terhadap bobot basah tanaman per tanaman. Pertumbuhan dan hasil terbaik bawang putih di dataran rendah terdapat pada jarak tanam $10 \mathrm{~cm} \times 10 \mathrm{~cm}$. Perlakuan Dosis pupuk NPK berpengaruh nyata terhadap tinggi tanaman pada umur 30 dan 45 HST. Pertumbuhan dan hasil bawang putih di dataran rendah cenderung lebih baik pada dosis pupuk NPK $400 \mathrm{~kg} \mathrm{ha}^{1}$. Terdapat interaksi yang tidak nyata anatar jarak tanam dengan dosis pupuk NPK terhadap pertumbhan dan hasil tanaman bawang putih di dataran rendah.
\end{abstract}

Kata kunci: Jarak tanam, dosis pupuk NPK dan bawang putih

\begin{abstract}
This study aims to determine the effect of spacing and the right dose of NPK fertilizer as well as the interaction between these two factors on the growth and yield of garlic plants in the lowlands. This research was carried out at the Experimental Gardens II East Sector and the Seed Science and Technology Laboratory, Faculty of Agriculture, Syiah Kuala University, taking place from January to April 2021. The research design used was a $3 \times 3$ factorial randomized block design with 3 replications. The factors studied were plant spacing consisting of 3 levels, namely $10 \mathrm{~cm} \mathrm{x}$ $10 \mathrm{~cm}, 10 \mathrm{~cm} \times 15 \mathrm{~cm}, 10 \mathrm{~cm} \times 20 \mathrm{~cm}$ and the dose of NPK fertilizer consisted of 3 levels, namely 400,600 and $800 \mathrm{~kg} \mathrm{ha}^{-}$. The results showed that plant spacing had a very significant effect on tuber weight per plot and yield potential, significantly affected wet plant weight per plant. The best growth and yield of garlic in the lowlands was found at a spacing of $10 \mathrm{~cm} \times 10 \mathrm{~cm}$. Treatment he dose of NPK fertilizer had a significant effect on plant height at the age of 30 and 45 DAP. The growth and yield of garlic in the lowlands tended to be better at a dose NPK fertilizer of $400 \mathrm{~kg}$ ha- ${ }^{1}$. There is an unreal intraction between plant spacing and dose NPK fertilizer of the growth and the garlic plant in lowland.
\end{abstract}

Keywords: Planting distance, dose of NPK and Garlic fertilizer

\section{PENDAHULUAN}

\section{Latar Belakang}

Bawang putih (Allium sativum L.) ialah komoditi pertanian penting di Indonesia yang banyak digunakan sebagai bumbu penyedap masakan, sebagai bahan yang digunakan dalam industri makanan dan bahan obat-obatan. Kebutuhan bawang putih tiap tahunnya terus bertambah bersamaan bertambahnya jumlah penduduk (Pusat Data dan Sistem Informasi Pertanian, 2017).

Bersumber dari informasi Badan Pusat Statistik (2019), kebutuhan bawng putih di Indonesia diperkirakan mencapai 500 ribu ton ha $^{-1}$. Produksi bawang putih Indonesia selama 5 tahun terakhir produksinya masih kurang dimana pada tahun 2018 mencapai 39.30 ton dengan luas panen 5.01 ribu ha, pada tahun 2019 
mencapai 88.29 ton dengan luas panen 12.28 ha, untuk mengatasi kekurangan bawang putih di Indonesia, maka perlu melakukan impor dari negara lain.

Produksi tanaman bawang putih dapat ditingkatkan dengan menggunakan varietas unggul. Varietas unggul bawang putih telah ada yang cocok dengan keadaan daerah, sesuai rujukan petani dan kebutuhan pasar. Varietas Lumbu Hijau dapat dibudidayakan untuk ketinggian 99-1.100 meter dari permukaan laut (dpl), varietas Lumbu Kuning untuk ketinggian 600-900 m dpl, varietas Lumbu Putih untuk ketinggian sekitar 6-200 m dpl, varietas Super Putih sesuai untuk ketinggian 900-1.000 m dpl dan varietas Super Kuning dapat dibudidayakan pada daerah yang mempunyai ketinggian 600-900 m dpl (Titisari et al., 2019). Penanaman bawang putih dengan berbagai varietas harus menggunakan budidaya yang tepat.

Budidaya bawang putih memerlukan jarak tanam yang tepat, karena mempengaruhi kepadatan populasi tumbuhan per satuan luas yang berefek pada hasil panen. Jika terlalu dekat akan mempengaruhi penerimaan cahaya matahari oleh tanaman, kompetisi antara tanaman saat menyerap air dan unsur hara. Selain itu jarak tanam juga dapat mempengaruhi kelembaban udara disekitar pertanaman yang berpengaruh terhadap pertumbuhan cendawan penyebab penyakit tanaman (Nazhira, 2014).

Jarak tanam yang umum bagi tanaman bawang putih ialah $10 \mathrm{~cm}$ x $15 \mathrm{~cm}$ dan $12,5 \mathrm{~cm}$ x $15 \mathrm{~cm}$ untuk benih seberat sekitar $1,5 \mathrm{~g}$. Benih yang lebih besar dengan berat $3 \mathrm{~g}$ bisa menggunakan jarak tanam $20 \mathrm{~cm}$ x $20 \mathrm{~cm}$ dan $20 \mathrm{~cm}$ x 25 $\mathrm{cm}$ untuk mengoptimalkan pertumbuhan umbi dalam tanah (Sandrakirana et al., 2018). Hasil maksimal tanaman bawang putih pada penggunaan jarak tanam 10 $\mathrm{cm} \times 10 \mathrm{~cm}$, kombinasi ukuran siung sebab jarak tanam berpengaruh terhadap tinggi, berat kering tanaman dan hasil bawang putih (Efendi et al., 2020). Hasil penelitian Saputra dan Yelni (2020) menyatakan bahwa perlakuan jarak tanam yang cocok di dataran rendah dan tanah miskin hara Muara Bungo ialah $10 \mathrm{~cm} \mathrm{x}$ $10 \mathrm{~cm}$.

Selain jarak tanam yang tepat dalam meningkatkan produksi bawang putih ialah melakukan pemupukan. Pemupukan merupakan upaya untuk penyediaan unsur hara baik makro dan mikro dengan upaya memperoleh pertumbuhan dan perkembangan tanaman yang lebih bagus. Pemupukan berguna untuk menjamin ketersediaan hara secara optimum untuk tanaman. Pupuk terbagi atas 2 yaitu pupuk organik dan pupuk kimia, salah satu pupuk kimia yaitu pupuk NPK.

Pupuk Nitrogen Phosphate (NPK) ialah salah satu pupuk kimia yang bisa dipakai untuk meninggikan kesediaan unsur hara makro (N, P dan K). Pupuk Phonska (15:15:15) ialah pupuk majemuk mengandung Nitrogen (N) 15\%, Fosfor $\left(\mathrm{P}_{2} \mathrm{O}\right) 15 \%$, Kalium $\left(\mathrm{K}_{2} \mathrm{O}\right) 15 \%$, Sulfur $(\mathrm{S}) 10 \%$ dan kadar air sebanyak $2 \%$. Pupuk majemuk ini hampir semua tercampur dalam air, sehingga unsur hara yang dikandungnya bisa cepat diabsorbsi tanaman dengan efektif (Kaya, 2013).

Tanaman bawang putih membutuhkan pupuk NPK sebesar $600 \mathrm{~kg} / \mathrm{ha}$ dengan tiga kali pemberian. Pemberian pupuk NPK pertama yaitu pada umur 15 hari setelah tanam (HST) dengan dosis $100 \mathrm{~kg} / \mathrm{ha}$, pemupukan kedua pada umur 35 HST dengan dosis $200 \mathrm{~kg} / \mathrm{ha}$ dan pemupukan ketiga pada umur 55 HST dengan dosis $300 \mathrm{~kg} / \mathrm{ha}$ (Sandrakirana et al., 2018). Selain penggunaan pupuk 
kandang, tanaman bawang putih diberikan pupuk lanjutan ialah pupuk NPK dosis $600 \mathrm{~kg} / \mathrm{ha}$ dengan cara ditaburkan antara barisan (Lingga dan Marsono, 2013).

Berdasarkan permasalahan tersebut penting dilaksanakan percobaan mengenai jarak tanam dan dosis pupuk NPK yang sesuai terhadap pertumbuhan dan hasil tanaman bawang putih di dataran rendah.

\section{METODOLOGI PENELITIAN}

\section{Tempat dan Waktu}

Penelitian telah dilakukan pada Lahan Penelitian II Sektor Timur, Laboratorium Ilmu dan Teknologi Benih Fakultas Pertanian Universitas Syiah Kuala, Darussalam, Banda Aceh. Penelitian telah dilakukan pada bulan Januari hingga April 2021.

\section{Alat dan Bahan}

Alat yang dipakai pada penelitian ini ialah pisau, gunting, cangkul, meteran, gembor, tali rafia, handsprayer, penggaris, papan nama, alat tulis, kamera, jangka sorong, timbangan digital dan timbangan duduk. Bahan yang dipakai dalam penelitian ini ialah bibit bawang putih varietas Lumbu Putih sebanyak 1.980 bibit (6 kg) dan 100 bibit untuk cadangan, pupuk kandang sebanyak $27 \mathrm{~kg}$, insektisida imidakloprid 5\% sebanyak 1 botol $(100 \mathrm{ml})$, fungisida mankozeb sebanyak 1 bungkus ( $200 \mathrm{~g}$ ) dan pupuk NPK sebanyak 1,65 kg.

\section{Rancangan Percobaan}

Racangan yang dimanfaatkan pada percobaan ini ialah Rancangan Acak Kelompok (RAK) pola faktorial 3x3 dengan 3 ulangan sehingga diperoleh 27 satuan percobaan, ada dua faktor yang diteliti. Faktor pertama ialah jarak tanam terdiri tiga taraf yaitu $J_{1}=10 \mathrm{~cm} \times 10 \mathrm{~cm}, J_{2}=10 \mathrm{~cm} \times 15 \mathrm{~cm}, J_{3}=10 \mathrm{~cm} \times 20 \mathrm{~cm}$. Faktor kedua adalah dosis pupuk NPK yang terdiri 3 taraf yaitu $\mathrm{N}_{1}=400 \mathrm{~kg} / \mathrm{ha}$, $\mathrm{N}_{2}=600 \mathrm{~kg} / \mathrm{ha}$ dan $\mathrm{N}_{3}=800 \mathrm{~kg} / \mathrm{ha}$.

\section{Pelaksanaan Penelitian}

\section{Persiapan lahan dan pembuatan bedengan}

Tanah (lahan) dibersihkan dari bekas tanaman tumbuhan sisa, rerumputan, semak, ataupun batu/krikil. Berikutnya lahan diolah hingga lumayan dalam dan strukturnya gembur dengan memakai cangkul. pengolahan tanah diawali 10 hari sebelum tanam dan bisa dilakukan 2 kali dengan selang waktu 3 hari. Pembuatan bedengan dengan ukuran $100 \mathrm{~cm}$ x $100 \mathrm{~cm}$, ketinggian $50 \mathrm{~cm}$ dan jarak antara bedengan $30 \mathrm{~cm}$ dan jarak antara ulangan $50 \mathrm{~cm}$. Pemberian pupuk dasar yaitu pupuk kandang diberikan selesai bedengan dibuat dengan dosis 10 ton/ha, pemberian pupuk kandang pada bedengan diaduk rata dengan tanah. Setelah diberikan pupuk kandang, lahan dibiarkan selama 1 minggu.

\section{Persiapan bibit}

Bawang putih diperbanyak dengan siung. Umbi bawang putih yang baik digunakan sebagai bibit mempunyai ciri-ciri sebagai berikut: Benih berasal dari umbi dan siung yang segar dan telah disimpan selama 8 bulan, pilih siung bagian tepi umbi dengan berat 1,5-1,9 $\mathrm{g}^{\text {siung }^{-1}}$, pangkal batang bernas dan keras, siung 
bernas (licin, segar dan tiada kerut) dan bebas dari hama penyakit dan mempunyai daya tumbuh lebih dari 85\% (Sandrakirana et al., 20180. Bibit yang digunakan harus dipotong $3 / 4$ bagian ujung siung bawang putih, siung bawang putih yang dipotong, pertama direndam dengan fungisida Dithane M-45 yang berbahan aktif Mankozeb $10 \mathrm{cc} \mathrm{L}^{-1}$ air selama 10 menit guna untuk mencegah serangan jamur fusarium, setelah keluar calon tunas bibit siap ditanam.

\section{Penanaman}

Sebelum ditanam tanah disiram terlebih awal agar menjadi lembab sehingga memudahkan saat penanaman. Pembuatan lubang tanam untuk bawang putih dilakukan sesuai dengan perlakuan penelitian, yaitu dengan jarak tanam $J_{1}=10 \mathrm{~cm} \times 10 \mathrm{~cm}, J_{2}=10 \mathrm{~cm} \times 15 \mathrm{~cm}$ dan $J_{3}=10 \mathrm{~cm} \times 20 \mathrm{~cm}$. Bawang putih ditanam sedalam $3 \mathrm{~cm}$, setiap lubang ditanami satu siung bawang putih sampai ujung siung rata dengan rata dengan permukaan tanah.

\section{Penyulaman}

Penyulaman dilakukan terhadap bibit yang yang pertumbuhannya kurang baik dan bibit yang mati, penggantian tanaman dilaksanakan setelah penanaman berumur 1 minggu.

\section{Pemupukan}

Pupuk yang dipakai ialah pupuk NPK dengan dosis sesuai perlakuan dimana $\mathrm{N}_{1}=400 \mathrm{~kg} / \mathrm{ha}$ (40 g/bedengan), $\mathrm{N}_{2}=600 \mathrm{~kg} / \mathrm{ha}(60 \mathrm{~g} /$ bedengan $)$ dan $\mathrm{N}_{3}=800 \mathrm{~kg} / \mathrm{ha}$ (80 g/bedengan). Pemupukan diberikan begitu tanaman sudah berumur 15, 35 dan 55 HST, pemberian pupuk NPK dilakukan secara larikan antara tanaman.

\section{Pemeliharaan}

\section{Pembersihan dan pembumbunan}

Pembersihan dikerjakan manual yaitu membersihkan bedengan dari rerumputan, penyiangan dilakukan begitu tanaman berumur 2 dan 4 minggu setelah tanam (MST). Sedangkan pembumbunan dikerjakan untuk penutupan umbi dan perakaran bawang putih yang keluar guna untuk memperkuat tanaman agar tidak rebah dan menghasilkan umbi yang bagus dan memperbaiki sirkulasi udara, air dalam tanah dan mempermudah pertumbuhan umbi.

\section{Penyiraman}

Penyiraman dilakukan sesuai dengan kondisi dilapangan, apabila hujan yang cukup penyiraman tidak dilakukan dan apabila tidak terjadi hujan maka penyiraman dilaksanakan setiap pagi dan sore hari. Penyiraman diakhiri saat tanaman telah tua atau menyambut panen yaitu begitu daun tanaman telah tiba menguning.

\section{Penanganan hama dan penyakit}


Penanganan hama dilakukan dengan penyemprotan insektisida yang berbahan aktif Confidor 200 SL yang merupakan jenis insektisida sistemik yang bekerja secara toksin kontak dan lambung, berbentukan pekatan coklat jernih yang bisa larut dalam air dengan konsentrasi $1 \mathrm{ml} \mathrm{L}^{-1}$ air diberikan pada tanaman bawang putih mulai diserbu hama. Penanganan penyakit dilaksanakan dengan penyemprotan fungisida mangkozeb Dithane M-45 dengan konsentrasi $2 \mathrm{~g} \mathrm{~L}^{-1}$ air diberikan pada saat umbi tanaman bawang putih terlihat berjamur ketika pagi atausore hari.

\section{Panen}

Kriteria bawang putih siap dipanen apabila 40-50\% daunnya telah menguning dan kering, pangkal batangnya terasa keras. Umur panen tanaman bawang putih berkisar antara 110 HST. Pemanenan dilakukan pagi hari dengan cara menggali rumpun tanaman bawang putih dengan cara menggunakan alat yang terbuat dari kayu dan dapat juga digali menggunakan tangan.

\section{Peubah pengamatan}

1. Tinggi tanaman $(\mathrm{cm})$

Pengukuran dilaksanakan pada sampel umur 15 dan 30 HST, pengukuran tinggi tanaman dilaksanakan dari permukaan tanah atau pangkal batang yang sudah diberi tanda dengan sampai pucuk daun tertinggi.

2. Jumlah siuang per umbi

Banyaknya siung per umbi tanaman dihitung sesudah dilakukannya pemanenan.

3. Diameter umbi ( $\mathrm{mm})$

Pengukuran diameter umbi diukur bagian tengah umbi bawang putih tanaman sampel menggunakan jangka sorong setelah di panen.

Ditimbang dengan timbangan digital per tanaman setelah dikeringanginkan selama 7 hari.

4. Bobot umbi per plot netto $(\mathrm{g})$

Mengkonversi rerata berat umbi per plot netto. Plot netto adalah tanaman dalam plot kecuali tanaman pinggir.

\section{HASIL DAN PEMBAHASAN}

\section{Pengaruh Jarak Tanam terhadap Pertumbuhan dan Hasil Tanaman Bawang Putih di Dataran Rendah}

Hasil analisis ragam menunjukkan bahwa perlakuan jarak tanam berpengaruh sangat nyata terhadap berat umbi per plot netto, berpengaruh nyata terhadap bobot berangkasan basah per tanaman dan berpengaruh tidak nyata terhadap tinggi tanaman pada umur 15 dan 30 HST, jumlah siung, diameter umbi yang bisa dilihat pada Tabel 1 .

Tabel 1. Rerata pertumbuhan dan hasil tanaman bawang putih di dataran rendah akibat perlakuan jarak tanam 


\begin{tabular}{|c|c|c|c|c|c|}
\hline \multirow{2}{*}{\multicolumn{2}{|c|}{ Peubah }} & \multicolumn{3}{|c|}{ Jarak tanam $(\mathrm{cm} \mathrm{x} \mathrm{cm})$} & \multirow{2}{*}{$\begin{array}{c}\text { BNT } \\
0,05\end{array}$} \\
\hline & & $J_{1}$ & $\begin{array}{c}\mathrm{J}_{2} \\
10 \times 15\end{array}$ & $\begin{array}{c}\mathrm{J}_{3} \\
10 \times 20\end{array}$ & \\
\hline \multirow{2}{*}{ Tinggi tanaman $(\mathrm{cm})$} & $15 \mathrm{HST}$ & 15,82 & 14,94 & 15,90 & - \\
\hline & $30 \mathrm{HST}$ & 22,46 & 21,02 & 21,83 & - \\
\hline \multicolumn{2}{|c|}{ Jumlah siung per tanaman } & 3,27 & 3,33 & 3,18 & - \\
\hline \multicolumn{2}{|l|}{ Diameter umbi (mm) } & 18,89 & 18,52 & 17,84 & - \\
\hline \multicolumn{2}{|c|}{ Bobot umbi per plot netto (g) } & $53,77 \mathrm{~b}$ & $40,53 \mathrm{a}$ & $32,42 \mathrm{a}$ & 11,82 \\
\hline
\end{tabular}

Keterangan: Angka yang diikuti huruf sama pada baris yang sama berbeda tidak nyata pada taraf $0,05 \%$ (uji $\mathrm{BNT}_{0,05}$ ); J= Jarak tanam.

Dari hasil penelitian ini menunjukkan bahwa pertumbuhan dan hasil tanaman bawang putih cenderung lebih baik ditemui pada perlakuan jarak tanam $10 \mathrm{~cm} \times 10 \mathrm{~cm}$. Prihal ini ikarenakan makin rapat jarak tanam maka populasi tanaman semakin banyak. Sesuai pendapat Alam et al, (2017). Jarak tanam $10 \mathrm{~cm}$ x $10 \mathrm{~cm}$ dapat digunakan dalam produksi bawang putih untuk mendapatkan hasil yang maksimal. Populasi yang lebih banyak diperoleh pada jarak tanam $10 \mathrm{~cm} \mathrm{x}$ $10 \mathrm{~cm}$ sehingga bobot per satuan luasnya akan lebih besar (Rajiman, 2011). Semakin rapat jarak tanam $10 \mathrm{~cm}$ x $10 \mathrm{~cm}$ menghasilkan tinggi tanaman tertinggi (Yadav et al., 2020).

\section{Pengaruh NPK terhadap Pertumbuhan dan Hasil Tanaman Bawang Putih di Dataran Rendah}

Hasil analisis ragam memperlihatkan kalau perlakuan dosis pupuk NPK berpengaruh nyata terhadap tinggi tanaman pada umur 30, 45 HST dan berpengaruh tidak nyata terhadap jumlah siung, diameter umbi dan bobot umbi per plot netto yang bisa dilihat pada Tabel 2 .

Tabel 2. Rerata pertumbuhan dan hasil tanaman bawang putih di dataran rendah akibat perlakuan dosis pupuk NPK

\begin{tabular}{lccccc}
\hline \multirow{2}{*}{ Peubah } & \multicolumn{3}{c}{ Dosis pupuk NPK $\left(\mathrm{kg} \mathrm{ha}^{-1}\right)$} & \multirow{2}{*}{ BNT } \\
\cline { 2 - 4 } & & $\mathrm{N}_{1=400} 400$ & $\mathrm{~N}_{2=600}$ & $\mathrm{~N}_{3=800}$ & 0,05 \\
\hline \multirow{2}{*}{ Tinggi tanaman (cm) } & $15 \mathrm{HST}$ & 15,78 & 14,82 & 16,06 & - \\
\multirow{2}{*}{ Jumlah siung per tanaman } & $22,82 \mathrm{ab}$ & $20,49 \mathrm{a}$ & $22,00 \mathrm{~b}$ & 1,62 \\
Diameter umbi (mm) & 3,44 & 3,11 & 3,22 & - \\
Berat umbi per plot netto (g) & 19,07 & 18,11 & 18,07 & - \\
\hline
\end{tabular}

Keterangan: Angka yang diiringi huruf yang sama pada baris yang sama berbeda tidak nyata pada taraf $0,05 \%$ (uji $\mathrm{BNT}_{0,05}$ ); J= Jarak tanam.

Hasil penelitian menunjukkan bahwa pertumbuahan dan hasil tanaman bawang putih di dataran rendah cenderung lebih baik dijumpai pada pemberian dosis pupuk NPK $400 \mathrm{~kg} \mathrm{ha}^{-1}$, walaupun secara statistik berbeda tidak nyata dengan pemberian dosis pupuk NPK lainnya. Hal ini diduga dosis pupuk NPK $400 \mathrm{~kg} \mathrm{ha}^{-1}$ sudah memenuhi kebutuhan untuk pertumbuhan dan hasil tanaman bawang putih di dataran rendah. Sesuai dengan pernyataan Hasibuan, (2006) menyatakan pupuk NPK dengan dosis $400 \mathrm{~kg} \mathrm{ha}^{-1}$ sudah dapat memenuhi kebutuhan yang dibutuhkan untuk pertumbuhan dan hasil tanaman bawang merah. Aplikasi kombinasi pupuk anorganik dan organik ditujukan untuk memperbaiki ketersediaan hara dalam tanah yang seimbang dan mencukupi kebutuhan tanaman bawang putih (Wisardja, 2017). 


\section{KESIMPULAN}

Pengaruh jarak tanam berpengaruh sangat nyata terhadap berat umbi per plot netto dan potensi hasi. Berpengaruh nyata terhadap bobot berangkasan basah per tanaman. Pertumbuhan dan hasil tanaman bawang putih di dataran rendah terbaik dijumpai pada jarak tanam $10 \mathrm{~cm}$ x $10 \mathrm{~cm}$. Dosis pupuk NPK berpengaruh nyata terhadap tinggi tanaman pada umur 30 dan 45 HST. Pertumbuhan tanaman bawang putih di dataran rendah yang lebih baik dijumpai pada dosis pupuk NPK $400 \mathrm{~kg} \mathrm{ha}^{-1}$. Terdapat interaksi yang tidak nyata antara jarak tanam dan dosis pupuk NPK terhadap pertumbuhan dan hasil tanaman bawang putih di dataran rendah.

\section{DAFTAR PUSTAKA}

Alam, M. S., Rahim, M. A., Bhuyan, M. A. H., Simon, P. W. dan Malek, M. A., 2017. Effect of Spacing on Growth and Yielld of Two Line of Garlic Under Dry Land Condition. Agrofor. Environ., 4(2), pp.151-154.

Badan Pusat Statistik. 2019. Data Produksi Tanaman Bawang Putih di Indonesia. Jakarta: Badan Ketahanan Pangan Kementerian Pertanian.

Efendi, A. M., Fahmi, I. Samanhudi dan Purwanto E., 2020. Pengaruh Ukuran Siung dan Jarak Tanam terhadap Petumbuhan dan Hasil Tanaman Bawang Putih Varietas Lumbu Hijau. Jurnal Agrotech. Res. 4(1), pp.6-10.

Hasibuan, B. E. 2006. Pupuk dan Pemupukan. Medan: USU Press.

Kaya, E. 2013. Pengaruh Kompos Jerami dan Pupuk NPK terhadap N-Tersedia Tanah Serapan N Pertumbuhan dan Hasil Padi Sawah (Oryza sativa L.). Jurnal Agrologia, 2(1), pp.43-50.

Lingga, P. dan Marsono. 2013. Petunjuk Pengguna Pupuk. Jakarta: Penebar Swadaya.

Nazhira, S. 2014. Pengaruh jarak tanam dan Jumlah Umbi terhadap Pertumbuhan dan Hasil Bawang Merah (Allium ascalonium L.). Universitas Syiah Kuala, Banda Aceh.

Pusat Data dan Sistem Informasi Pertanian Kementerian Pertanian. 2017. Konsumsi dan Neraca Penyediaan Penggunaan Bawang Putih. Buletin Triwulan Konsumsi Pangan, 8(2), pp.25-30.

Rajiman. 2011. Aplikasi Pembenahan Tanah dan Jarak Tanam di Lahan Pasir Pantai untuk Produksi Bawang Merah, Jurnal Teknologi, 2, pp.82-92.

Sandrakirana, R., Fauzia, I., Alami, E. N., Aisyawati, Rahmawati, D., Handayani, W., Susanti, I. dan Baswarsiati. 2018. Panduan Budidaya Bawang Putih. Malang: Balai Pengkajian Teknologi Pertanian.

Saputra, A. dan Yelni, G., 2020. Perbedaan Jarak tanam terhadap Pertumbuhan dan Hasil Bawang Putih (Allium sativum L.) di Dataran Rendah. Jurnal Sains Agro, 5(1), pp.1-8.

Titisari, A., Setyorini, E., Sutriswanto, S. dan Suryantini, H., 2019. Kiat Sukses Budidaya Bawang Putih. Bogor: Pusat Perpustakaan dan Penyebaran Teknologi Pertanian. 
Wisardja, I. P., Lana, W. dan Rusdianti, I. G. M., 2017. Pertumbuhan dan Hasil Tanaman Bawang Putih (Allium sativum L.) Varietas Lumbu Putih Akibat Penggunaan Dosis Pupuk Organik dan Kerapatan Tanam. Majalah Ilmiah Untab, 14(2), pp.209-215.

Yadav, S., Kumar, S. dan Singh, S., 2020. Pengaruh Varietas dan Jarak Tanam yang Berbeda terhadap Pertumbuhan dan Hasil Sifat Bawang Putih (Allium sativum L.). Jurnal Ekologi India, 47(3), pp.863-865. 